\title{
Assessment of Operative Management of Bimalleolar Fractures of Ankle Joint
}

\author{
Pravas Kumar ${ }^{1}$, Abhishek ${ }^{1}$, Shree Prakash Singh ${ }^{2}$ \\ ${ }^{1}$ Senior Resident, Department of Orthopaedics, Anugrah Narayan Magadh Medical College and Hospital, Gaya Bihar, ${ }^{2}$ Professor and Head, Department of \\ Orthopaedics, Anugrah Narayan Magadh Medical College and Hospital, Gaya Bihar.
}

\section{Abstract}

Background: Bimalleolar fractures have shown to have worse outcomes. The present study was conducted to assess operative management of bimalleolar fractures of ankle joint. Subjects and Methods: The present study was conducted on 60 cases of bimalleolar fractures of ankle joint. Patients with compound fractures, pilon fractures, syndesmotic injuries were excluded. In all patients, reason of fracture and operative outcome was recorded. Results: Functional outcome was excellent seen in 15, good in 30, fair in 12 and poor in 3 . The difference was significant $(\mathrm{P}<0.05)$. Post operative complications were superficial skin infection seen in 2 and restricted ankle movement in 1. Conclusion: Bimalleolar fractures of ankle joint are common amongst males. In maximum cases, good results were obtained.

Keywords: Ankle, Bimalleolar, fractures.

Corresponding Author: Dr. Abhishek, Senior resident, Department of Orthopaedics, Anugrah Narayan Magadh Medical College and Hospital, Gaya Bihar.

Received: January 2019

Accepted: February 2019

\section{Introduction}

Ankle fractures are among the most common joint injuries of the lower extremity, and have been identified as a significant source of morbidity for both the young and the elderly. Especially among the elderly, who have a number of comorbidities, ankle fractures are becoming increasingly common. ${ }^{[1]}$

For a good long-term functional outcome to be achieved, reliable early evaluation is crucial so that it can be determined whether the problem is a distorsion (sprain), ligament rupture, bony ligament avulsion, or fracture of the talocrural joint. The proper treatment is chosen on the basis of the mechanism of the accident and the correct classification of the injury and accompanying soft-tissue damage. ${ }^{[2]}$

Ankle fractures are generally to be regarded as joint fractures even if there is no fracture cleft in any of the articular surfaces of the joint. For the ankle joint in particular, non-anatomical reductions and restraints lead to premature degeneration of the joint. Thus, proper anatomical reconstruction - generally involving surgery-is needed to prevent posttraumatic degeneration over the long term. In the elderly, perioperative risk, and post-operative complications from skin infections, and the concurrent risks due to the presence of comorbid diseases are higher. ${ }^{[3]}$ Previously published studies have shown that short- and long-term outcomes after surgical intervention of unstable ankle fractures may have some residual function deficit.
Furthermore, bimalleolar fractures have shown to have worse outcomes than those associated with unimalleolar injuries. ${ }^{[4]}$ The present study was conducted to assess operative management of bimalleolar fractures of ankle joint.

\section{Subjects and Methods}

The present study was conducted in the department of Orthopaedics from Oct 2017 to Nov 2018 at Anugrah Narayan Magadh Medical College and Hospital, Gaya Bihar. It comprised of 60 cases of bimalleolar fractures of ankle joint. All patients were informed regarding the study and written consent was obtained. Ethical clearance was taken from institutional ethical committee.

\section{Inclusion criteria}

- Subjects with presence of any malleolar fracture of ankle joint.

- Subjects within the age group of 15 years to 45 years

- Subjects medically fit for surgery.

\section{Exclusion criteria}

- A previous fracture of either ankle,

- Open ankle fracture,

- A fracture and open epiphyses,

- Diabetic and hypertensive patients

General information such as name, age, gender etc. was recorded. In all patients, reason of fracture and operative outcome was recorded. Results thus obtained were 
subjected to statistical analysis. $\mathrm{P}$ value less than 0.05 was considered significant.

Results

[Table 1] shows that out of 60 patients, males were 40 and females were 20. [Table 2] shows that mode of injury was road side accidents seen in 15 males and 8 females, sports injury in 10 males and 6 females, fall in 9 males and 4 females and domestic violence in 6 males and 2 females. The difference was significant $(\mathrm{P}<0.05)$. [Figure 1] shows that functional outcome was excellent seen in 15, good in 30, fair in 12 and poor in 3. The difference was significant $(\mathrm{P}<$ 0.05). [Graph 2] shows that post operative complications were superficial skin infection seen in 2 and restricted ankle movement in 1 .

\begin{tabular}{l}
\hline Table 1: Distribution of patients \\
\begin{tabular}{|l|l|l|}
\hline Total- 60 & Males & Females \\
\hline Gender & 40 & 20 \\
\hline Number &
\end{tabular} \\
\hline
\end{tabular}

\section{Table 2: Mode of injury.}

Table 2: Mode of injury.
\begin{tabular}{|l|l|l|l|}
\hline Mode & Males & Females & P value \\
\hline $\begin{array}{l}\text { Road side } \\
\text { accidents }\end{array}$ & 15 & 8 & 0.05 \\
\hline Sports injury & 10 & 6 & \\
\hline Fall & 9 & 4 & \\
\hline $\begin{array}{l}\text { Domestic } \\
\text { violence }\end{array}$ & 6 & 2 & \\
\hline Total & 40 & 20 & \\
\hline
\end{tabular}

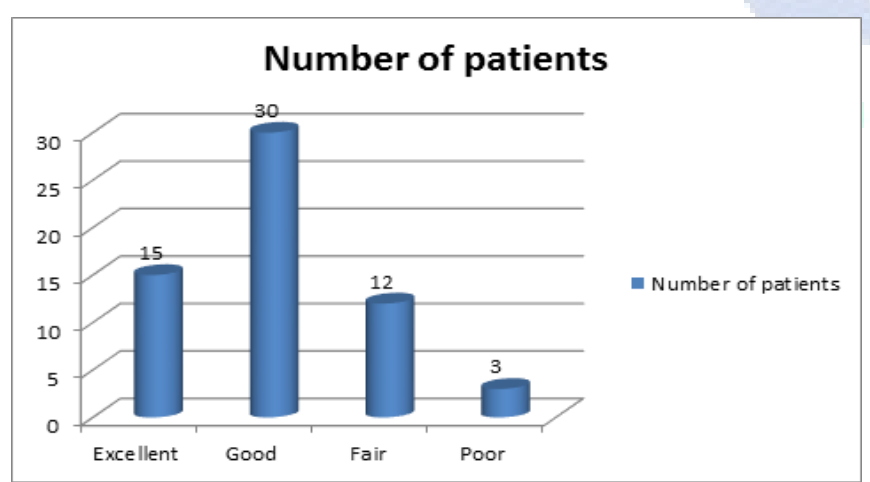

Figure 1: Functional outcome using Baird and Jackson score

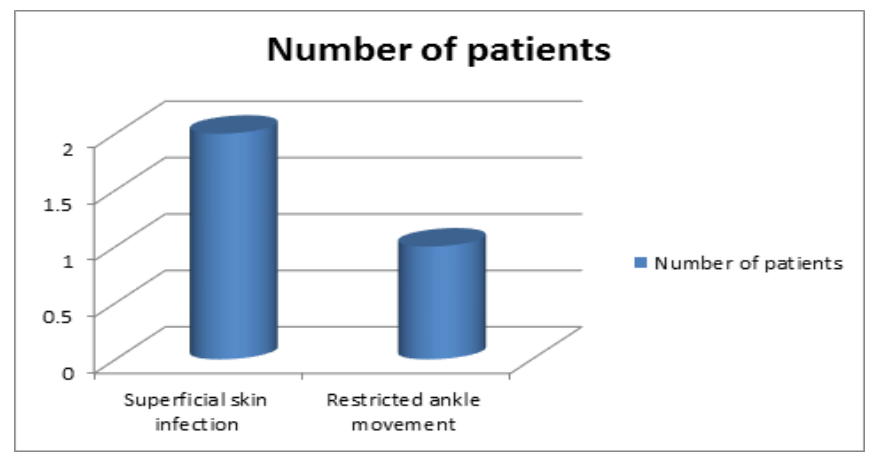

Figure 2: Post operative complications
When an ankle fracture has been diagnosed, the choice of a suitable treatment depends not only on the fracture type and associated injuries, but also on the patient's other medical conditions, and any treatment can only be provided with the patient's informed consent. Ankle fractures are initially evaluated by physical examination and then by x-ray. They can be classified according to either the AO Foundation (Association for the Study of Internal Fixation) or the Weber classification. Dislocated fractures need emergency treatment with immediate reduction; this is crucial for the prevention of hypoperfusion and nerve damage. 5

Bimalleolar fractures cause the loss of stability by disturbing the pillar structure \& there by reduces the tibiotalar contact area \& alters the joint congruity. Therefore achieving the pillar alignment \& joint congruity is the key to good outcome \& restores stable ankle Function. Initial workers tried to stabilize by closed reduction \& External plaster but failed because when the oedema subsided, the cast was loose $\&$ the reduction gave way producing very poor results. Also prolonged immobilization caused huge problem of fracture disease, especially in geriatric age group. It also increased the incidence of post traumatic arthritis. So open reduction $\&$ internal fixation became the dictom.6 The present study was conducted to assess operative management of bimalleolar fractures of ankle joint.

Out of 60 patients, males were 40 and females were 20. Table II shows that mode of injury was road side accidents seen in 15 males and 8 females, sports injury in 10 males and 6 females, fall in 9 males and 4 females and domestic violence in 6 males and 2 females. The difference was significant $(\mathrm{P}<0.05)$. Vioreanu et al7 found that average satisfactory results were obtained in all patients $(100 \%)$. The average union time was 9-10 wks (8-14 wks). Malleolar screws gave good results of fixation of med malleolus $(80 \%) \& 1 / 3$ rd tubular plate gave good results for lateral malleolus (Fibula) $87 \%$. K- wires \& TBW was a good option in osteoporotic Patients. Of the 38 cases acc to Ankle Society Criteria, 28 had good results (74\%) 8 had fair outcome $(21 \%) 2$ had poor results. Commonest Complication was joint stiffness \& superficial infection. Shah et al 8 found that mean age was $43.8 \pm 5.46$ years and 48 were male patients. Supination external rotation was the most commonly seen injury in our patient population. Postoperatively, superficial skin infections were seen in $15 \%$ and restricted ankle movement in $11 \%$ patients. According to the Baird and Jackson score, clinical functional outcome was excellent in 15 cases, good in 30, fair in 12 and poor in 3 patients. Patients aged less than 45 years and supination external rotation injuries were significantly associated with excellent and good functional outcomes as compared to patients of older age.

\section{Conclusion}

From the above results, the authors conclude that bimalleolar fractures of ankle joint are common amongst males. In maximum cases, good results were obtained. However; further studies are recommended. 


\section{References}

1. Mohapatra A, Raj K. Functional outcome after surgical treatment of ankle fracture using Baird Jackson score. Int J Res Orthop 2018;4:63841.

2. Appleton $\mathrm{P}, \mathrm{McQueen} \mathrm{M}$. The fibula nail for treatment of ankle fractures in elderly and high risk patients. Techniques Foot Ankle Surg. 2006;5(3):204-8.

3. Büchler L, Tannast M, Bonel HM, Weber M. Reliability of radiologic assessment of the fracture anatomy at the posterior tibial plafond in malleolar fractures. J Orthop Trauma. 2009;23(3):208-12.

4. Obremskey WT, Dirschl DR, Crowther JD, Craig WL III, Driver RE, LeCroy CM. Change over time of SF-36 functional outcomes for operatively treated unstable ankle fractures. J Orthop Trauma.
2002;16:30-3.

5. Hasselman CT, Vogt MT, Stone KL, Cauley JA, Conti SF. Foot and ankle fractures in elderly white women: incidence and risk factors. JBJS. 2003;85(5):820-4.

6. Makwana NK, Bhowal B, Harper WM, Hui AW. Conservative versus operative treatment for displaced ankle fractures in patients over 55 years of age: a prospective, randomised study. Bone \& Joint J. 2001;83(4):525-9.

7. Vioreanu M, Brophy S, Dudeney S, Hurson B, Kelly E, O’Rourke K, et al. Displaced ankle fractures in the geriatric population: operative or non-operative treatment. Foot Ankle Surg. 2007;13(1):10-4.

8. Shah NH, Sundaram RO, Velusamy A, Braithwaite IJ. Five-year functional outcome analysis of ankle fracture fixation. Injury. 2007; $38: 1308-12$.

Copyright: () the author(s), 2019. It is an open-access article distributed under the terms of the Creative Commons Attribution License (CC BY 4.0), which permits authors to retain ownership of the copyright for their content, and allow anyone to download, reuse, reprint, modify, distribute and/or copy the content as long as the original authors and source are cited.

How to cite this article: Kumar P, Abhishek, Singh SP. Assessment of Operative Management of Bimalleolar Fractures of Ankle Joint. Asian J. Med. Res. 2019;8(1):OR04-OR06.

DOI: dx.doi.org/10.21276/ajmr.2019.8.1.OR2

Source of Support: Nil, Conflict of Interest: None declared. 